\title{
Las Spanish-speaking Connections de Derrida
}

\author{
DeRRIDA's SPANISH-SPEAKING CONNECTIONS \\ Cristina de Peretti y Delmiro Rocha
}

Universidad Nacional de Educación a Distancia

Madri, Espanha

\section{Resumen}

En la primera parte de este artículo se proporciona una relación de los distintos viajes de Derrida a Espańa, de los mejores especialistas en su pensamiento (incluidos algunos de otros países de habla hispana), así como de las tesis doctorales que sobre él se han defendido en nuestro país. También se hace un breve balance de las monografías y de las traducciones de sus libros en lengua española. En la segunda parte, un joven especialista en Derrida narra la recepción de la deconstrucción en primera persona haciendo fuerte hincapié en el caso particular de Galicia, llevado a cabo desde los márgenes de la institución y desde la lusofonía.

Palavras-clave: Derrida; España; Galicia; lengua española; institución.

\section{Résumé}

Dans la première partie de cet article, nous dressons un rapport des voyages de Derrida en Espagne, des meilleurs spécialistes de sa pensée (y compris quelquesuns appartenant à d'autres pays de langue espagnole), ainsi que des thèses doctorales sur lui soutenues dans notre pays. Nous fournissons également un bref bilan des monographies, ainsi que des traductions de ses livres en espagnol. Dans la deuxième partie, un jeune spécialiste de la pensée de Derrida raconte en première personnel'accueil fait à la déconstruction en insistant très particulièrement dans le cas précis de la Galice : un accueil dans les marges de l'institution et à partir de la lusophonie.

Mots-clés: Derrida; Espagne; Galice; langue espagnole; institution.

\section{Abstract}

In the initial part of this article, there is an overview of the several trips made by Derrida to Spain, by the best specialists in his thinking (some of them from other Spanish-speaking countries), and the doctoral theses that have been defended in our country. A brief evaluation of monographs and translations in the Spanish language of his books is also made. In the second part, a young specialist in Derrida narrates the reception of the deconstruction in first person with strong emphasis on the particular case of Galicia, carried out from the margins of the institution and from the lusophony.

Keywords: Derrida; Spain; Galicia; Spanish language; institution.

Aunque, a lo largo de los años 70 del pasado siglo, las traducciones en lengua española de los textos de Derrida (sobre todo si tenemos también en cuenta las traducciones realizadas en Hispanoamérica) no eran excesivamente escasas, en las aulas de las universidades españolas era prácticamente imposi- 
ble escuchar su nombre. Tan sólo Ángel Currás, un joven profesor (que desgraciadamente moriría en 1979) de la Facultad de Filosofía de la Universidad Complutense de Madrid (UCM), dedicaba una buena parte de sus clases a hablar de todo ese pensamiento francés de la diferencia - por decirlo de una manera demasiado rápida y general - que, por aquel entonces, estaba ya en pleno apogeo. Así fue como yo (C.P.), ${ }^{1}$ junto con mis demás compañeros de carrera, escuché por primera vez el nombre de Jacques Derrida, el cual, a partir de ahí, ya me ha acompañado para siempre a lo largo de mi vida y de mi andadura filosófica.

A principios de la década de los años 80, en 1982 concretamente, conocí (C.P.) personalmente a Derrida, en la ya inexistente Universidad de Zorroaga (San Sebastián) en donde, durante el curso académico 1981-1982, Víctor Gómez Pin y otros profesores de dicha universidad le habían invitado a impartir un curso de doctorado de cuatro sesiones titulado "La filosofía como institución" (DERRIDA, 1984). En el mes de diciembre de ese mismo año 1982, Derrida vuelve a España para participar, junto al psicoanalista René Major, en un encuentro entre filosofía y psicoanálisis organizado por los Institutos franceses de Barcelona y de Madrid. Con ocasión de su viaje a Madrid, Derrida intervino asimismo, con algunos profesores de la UCM y de la Universidad Nacional de Educación a Distancia (UNED), en una mesa redonda sobre la función institucional de la filosofía. Tras estos dos viajes a España en 1982, Derrida no volvió a pisar suelo español hasta 1987. Y fue con motivo de participar nuevamente en otra mesa redonda, esta vez en torno a la ley, en un Simposio Internacional organizado por la Facultad de Filosofía de Zorroaga y el Collège International de Philosophie, y celebrado en la Facultad de Derecho de la Universidad de Valencia. En 1989, somos el prof. José Ma Ripalda y yo (C.P.) quienes, a nuestra vez, invitamos a Derrida a la UNED donde impartirá unas conferencias sobre Heidegger y sobre Benjamin (DERRIDA, 1994a, 1994b). Tras su estancia en Madrid, Derrida viaja asimismo a Barcelona para dar una conferencia en la Universidad Central y otra en la sede de la editorial Anthropos que, ese mismo año, había publicado varios textos de él y sobre él. ${ }^{2}$ En 1990 y 1994,

\footnotetext{
${ }^{1}$ Con la indicación (C.P.) apuntamos que las situaciones o los recuerdos a los que, en ese momento, se está aludiendo corresponden únicamente a Cristina de Peretti.

Sobre la recepción de Derrida en España se pueden consultar también otros dos artículos realizados hace ya muchos años y desde perspectivas bastante diferentes: FERRERO, L. y DE PERETTI, C. "La recepción en España del pensamiento de Jacques Derrida". En: Revista de Filosofía (Instituto de Filosofía "Luis Vives", C.S.I.C., Madrid), 2a serie, VI, enero-junio 1983 y DE PERETTI, C. "Mi vida en deconstrucción". En: Daimon. Revista de Filosofia (Universidad de Murcia), n. 19, 1999.

${ }^{2}$ Por un lado, un número de los "Suplementos. Antologías temáticas", con una selección de textos de Derrida titulada "¿Cómo no hablar? Y otros textos". En Anthropos. Revista de Documentación Cientifica de la Cultura, n. 13, marzo de 1989 (Dicha selección - aumentada - de textos de Derrida fue posteriormente reeditada en dos libros, uno con el ya mencionado título y otro con el título El tiempo
} 
Derrida viaja a Murcia, invitado por el prof. Patricio Peñalver, para impartir, en 1990, una conferencia que, posteriormente, se convertiría en su librito Moscou aller-retour y, en 1994, otra sobre las "mères porteuses" ("vientres de alquiler"). Tras esta última estancia suya en Murcia, Derrida visita una vez más la UNED de Madrid para hablar del "mal de archivo" (DERRIDA, 1995a, 1995b), de Freud y de Yerushalmi. También en la UNED, al día siguiente, se reúne a puerta cerrada con el Grupo Decontra (grupo permanente de investigación, creado en el curso 1991-1992, compuesto por profesores, estudiantes y licenciados de Filosofía que trabajamos sobre su pensamiento y versión más libre, por extraoficial, del muy posterior Grupo de investigación consolidado, reconocido por la UNED desde 2007, titulado "Deconstrucciones"). En 1997, nuevo viaje de Derrida a Madrid con una agenda bastante cargada: dos conferencias en el Instituto de Filosofía del Consejo Superior de Investigaciones Científicas; dos mesas redondas, una con filófosos y otra con arquitectos, en un encuentro organizado por la Escuela Técnica Superior de Arquitectos de Madrid y por la Fundación de Investigaciones Marxistas y, finalmente, otra reunión, en la UNED, a puerta cerrada con el ya mencionado Grupo Decontra. Dos años más tarde, en el mes de diciembre de 1998, Derrida vuelve a Madrid con motivo de presidir, de nuevo en la UNED, el tribunal encargado de juzgar la espléndida tesis doctoral de Paco Vidarte titulada "Una tesis en deconstrucción” (VIDARTE, 2001). Tras dicho acto, Derrida viaja a Valencia, invitado por el profesor de Teoría de la literatura y Literatura comparada Manuel Asensi, para clausurar (DERRIDA, 1999b) un ciclo de conferencias sobre "El futuro de la Teoría de la Literatura" organizado por el Instituto de Estudios de Retórica de Valencia. Asimismo, del 22 al 28 de febrero de 1999, Derrida vuelve de nuevo a Espańa, concretamente

de una tesis. Desconstrucción e implicaciones conceptuales. En: Barcelona: Proyecto "A" Ediciones, 1997) así como otro número monográfico sobre él titulado "Jacques Derrida. Una teoría de la escritura, la estrategia de la deconstrucción. Presencia del pensamiento de Derrida en España”. En: Anthropos. Revista de Documentación Científica de la Cultura, n. 93, febrero de 1989. Por otro lado, la editorial Anthropos publicaba también ese mismo año la traducción de La escritura y la diferencia (Trad. P. Peńalver. Barcelona: Anthopos, 1989) así como la primera monografía sobre Derrida publicada en España, reelaborada a partir de mi (C.P.) tesis doctoral, DE PERETTI, C. Jacques Derrida: texto y deconstrucción. Barcelona: Anthopos, 1989. Un año más tarde, en otra editorial también catalana, saldría la segunda monografía: PEÑALVER, P. La desconstrucción. Escritura y filosofía. Barcelona: Montesinos, 1990. A ambas, afortunadamente, les seguirían algunas más.

Una breve observación en la que quizás algunos lectores hayan reparado: en varios títulos de esta misma nota aparecen unas veces el término "deconstrucción" (sin "s") y, otras, el término "desconstrucción" (con "s"). Se trata de una pequeña polémica lingüística que hemos arrastrado durante muchos años Patricio Peñalver y yo (C.P.) y respecto a la cual nunca hemos logrado ponernos de acuerdo. Así que, en España, ambos términos conviven finalmente en armonía y, según sus procedencias o sus predilecciones, cada cual utiliza el término que más le apetece. Por su parte, la Real Academia de la lengua española admitió por fin, en la 22a edición (2001) de su diccionario, el término "deconstrucción". El término "desconstrucción" sólo aparece mencionado y con la siguiente salvedad: "la palabra desconstrucción no está registrada en el diccionario. La que se muestra a continuación tiene formas con una escritura cercana". Naturalmente, dicha palabra no es otra que "deconstrucción" (www.rae.es/recursos/diccionarios/drae). 
a Toledo y a Almería. Pero esta vez no se trata de impartir ninguna conferencia, de participar en ninguna mesa redonda ni de reunirse con ningún grupo afín a su pensamiento sino de rodar algunas escenas del - por así decirlo - documental D’ailleurs Derrida ${ }^{3}$ que la escritora y cineasta egipcia Safaa Fathy está filmando entonces sobre él. Por la semejanza que tienen con los paisajes de la infancia argelina de Derrida, en las tierras de Almería se rodarán algunas secuencias en las que parece que Derrida está recorriendo algunos lugares del país que le vió nacer. Por su parte, Toledo, la así llamada "ciudad de las tres culturas", cristiana, judía y musulmana, no es un lugar menos idóneo para que ese "marrano universal" -que, en tantas ocasiones, Derrida asegura ser- pasee por sus calles y visite su sinagoga, recordando el posible origen sefardí de su apellido y su "gusto por el secreto", o para que contemple el cuadro del Greco, "El entierro del Conde de Orgaz", rememorando a su madre (DERRIDA, 1999a). Como recuerdo mío personal (C.P.) de esta visita de Derrida a Toledo en 1999, permítaseme añadir que, pocos días antes, Derrida nos telefoneó a Paco Vidarte y a mí para anunciarnos su paso por Toledo e invitarnos a cenar con él esa noche. Finalmente, Derrida viaja por última vez a España en marzo de 2002. En esta ocasión es la profa Marta Segarra quien le invita a impartir, junto con Hélène Cixous, el primer "Seminario de Barcelona", (CIXOUS, Helène; DERRIDA, 2004) organizado por el Centre Dona i Literatura de la Universidad Central de dicha ciudad. Aunque, desgraciadamente, ya sin la presencia real de Derrida, no podemos por menos que recordar también aquí el primer y único Coloquio Internacional sobre Derrida que, por el momento, se ha celebrado en España (en Hispanoamérica, por el contrario, ya ha habido varios) y que, dentro del marco de un proyecto de investigación $\mathrm{I}+\mathrm{D}+\mathrm{i}$ concedido a nuestro grupo en 2006 por el entonces así llamado Ministerio de Educación y Ciencia español para la realización de la traducción de Glas, pudimos organizar en Madrid en febrero de 2010 con la participación no sólo de profesores y estudiantes espańoles sino también de algunos de los mejores especialistas internacionales del pensamiento de Derrida y asimismo con la presencia de su mujer, Marguerite Derrida (ESCRITURA, 2010).

Como puede deducirse de todo lo dicho hasta aquí, en España, es sin duda en el terreno de la filosofía, y en una medida quizás algo menor en el de la teoría y la crítica literaria, en donde el pensamiento y el trabajo de Derrida siempre han despertado el mayor interés y en donde han tenido y siguen teniendo la máxima repercusión. Además de los nombres ya citados con anterioridad, no queremos dejar de mencionar a otros profesores como Julián Santos y Fernando Rampérez

\footnotetext{
${ }^{3}$ Cf. la película de FATHY, Safaa. D'ailleurs Derrida. Gloria Films Production /La Sept Arte France, 1999 así como el libro de DERRIDA, Jacques; FATHY, Safaa. Tourner les mots. Au bord d’un film. Paris: Galilée, 2000.
} 
(UCM) - este último, desgraciadamente, de baja definitiva, por un problema de salud con consecuencias desastrosas -, Manolo Vázquez (Universidad de Valencia), Antonio Tudela (Universidad de Granada), José Bernal (al que últimamente le hemos perdido la pista pero que defendió una magnífica tesis sobre Derrida en 1998 en la Universidad de Granada (BERNAL, 2001) y que, no lo dudamos, sigue hoy por hoy trabajando sin descanso en la brecha derridiana) y Túa Blesa (Universidad de Zaragoza). Dentro de las generaciones más jóvenes, habría que nombrar también a Paco Vidarte (UNED, fallecido desgraciadamente en 2008), Antonio Aguilar (Universidad de Valencia), Laura Llevadot (Universidad Central de Barcelona), Cristina Rodríguez Marciel (UNED) así como a algunos "flamantes" doctores como Delmiro Rocha, Beatriz Blanco, Idoia Quintana, Fabio Vélez (Universidad mejicana de La Puebla) o Federico Rodríguez Gómez (actualmente becario postdoctoral del FONDECYT chileno y autor del ensayo Cantos cabríos. Jacques Derrida, un bestiario filosófico, que se publicará en Santiago de Chile: Fondo de Cultura Económica, 2015, con el que ganó, en 2013, el premio "Mejores Obras Literarias" del Consejo Nacional de la Cultura y las Artes de Chile). Pero tampoco queremos olvidarnos aquí de otros grandes expertos hispanohablantes en el pensamiento de Derrida como son los profesores chilenos Carlos Contreras e Iván Trujillo; las profesoras argentinas Mónica Cragnolini, Ana Paula Penchaszadeh, Gabriela Balcarce (Universidad de Buenos Aires) y Analía Gerbaudo (Universidad Nacional del Litoral) así como la profesora portoriqueña recientemente fallecida (2012) Mara Negrón (Universidad de Puerto Rico). Es más que probable que, por desconocimiento nuestro o por descuido, otros especialistas en Derrida, españoles e hisponoamericanos, hayan quedado fuera de esta lista. A todos ellos nuestras más sinceras disculpas.

A pesar de lo tediosa que, por su extensión, la anterior lista pueda resultarle al lector, en España (y aquí nos referimos exclusivamente a nuestro país, no al resto de países hispanohablantes cuyas "interioridades" ignoramos totalmente), la falta de conocimiento del pensamiento de Derrida y de reconocimiento a dicho pensamiento sigue siendo enorme. Y, aunque su nombre se suele obviar normalmente en los ámbitos universitarios (las reticiencias hacia su pensamiento todavía son tan grandes como el desconocimiento de sus textos), sí se recurre a veces (aunque cada vez menos, por suerte) al término "deconstrucción" (no sólo en el ámbito académico sino también en los medios de comunicación y, en ocasiones, publicitarios) sin saber siquiera de lo que se está hablando. Pese a todo ello, y aunque las monografías, colectivas o no, escritas en lengua española (esto es, no traducidas al español desde otro idioma) centradas exclusivamente en el trabajo de Derrida no son todavía lo numerosas que nos gustaría que fueran y que deberían ser, los artícu- 
los sobre él resultan prácticamente inabarcables. A todas estas publicaciones, podemos sumar también unos cuantos números monográficos dedicados exclusivamente a su obra. ${ }^{4}$

Por su parte, las traducciones en lengua española de los textos de Derrida, aunque no siempre de buena calidad, son bastante abundantes (lo cual se debe, en gran medida, más a la labor de las editoriales hispanoamericanas que de las españolas). Faltan, sin embargo, todavía por traducir algunos libros suyos que consideramos imprescindibles como son Psyché (hace unos años, Mónica Cragnolini estaba dirigiendo la edición de la traducción de este libro al español pero, que sepamos, todavía no se ha publicado), Points de suspension, Limited Inc. o Demeure. ¡Esperemos que los dos más recientes, el Séminaire La peine de mort de 1999-2000 y el - por el momento - último texto suyo publicado: Heidegger: la question de l'Être et l'Histoire, no caigan a su vez en el olvido de los editores hispanohablantes! Un punto y aparte merece, no obstante, la traducción de Glas, un texto traducido hace ya muchos años al inglés y, más recientemente, al italiano y al alemán. Dicho de otro modo, una laguna imperdonable en el haber de las traducciones de Derrida al español. Y más, si cabe, cuando, gracias al ya mencionado proyecto de investigación $\mathrm{I}+\mathrm{D}+\mathrm{i}$ concedido a nuestro grupo de trabajo (que contó asimismo, en esta ocasión, con profesores de otras universidades), de hecho, la traducción de Glas en lengua española ya está terminada: terminada tras numerosas revisiones e incontables horas de trabajo. Sin embargo, bien por falta de dinero (jsiempre la famosa crisis!) bien por falta de interés, por el momento ninguna editorial de nuestro país parece querer comprometerse a publicar ese Clamor en lengua española.

Finalmente, en lo que se refiere a las tesis doctorales dedicadas en exclusiva al trabajo de Derrida y defendidas en las universidades españolas, ${ }^{5}$ es tranquilizador comprobar que, tras las dos primeras, la de Anna Poca y la mía (C.P.), realizadas en los años 1980, y después de un largo paréntesis de casi una década, en 1998, se defendiesen ya nada menos que tres tesis en las uni-

\footnotetext{
${ }^{4}$ Además de los números de la revista Anthropos y del volumen de Escritura e imagen, en nuestro país contamos con los siguientes números de revista monográficos sobre Derrida: Suplemento Cultural de El Independiente (Madrid), 24 de diciembre de 1989; Daimon. Revista de Filosofia (Universidad de Murcia), n. 19, 1999; Revista Archipiélago (Madrid), n. 75, mayo de 2007 y "Dossier: Derivas derridianas de la literatura". En: Tropelias. Revista de Teoría de la literatura y literatura comparada (Universidad de Zaragoza), n. 19, 2013 (disponible en: <http://zaguan.unizar.es/ojs/index.php/tropelias).

${ }^{5}$ Bastante más numerosas son, por supuesto, las tesis doctorales que, sin estar centradas en el pensamiento de Derrida, a lo largo de sus páginas se refieren con frecuencia y no de forma accesoria a su obra. Entre otras, podríamos citar, evidentemente, las de Patricio Peñalver, Julián Santos, Fernando Rampérez, Laura Llevadot, Cristina Rodríguez Marciel, Idoia Quintana, Fabio Vélez o Antonio Aguilar. De nuevo, quedarán sin duda muchos otros nombres por mencionar y, por eso, de nuevo pedimos también disculpas. En todo caso, la relación de todas las tesis doctorales realizadas en España puede consultarse en la Base de Datos (TESEO) del Ministerio de Educación, Cultura y Deporte (siempre y cuando dicho servicio esté operativo, lo cual no ocurre con excesiva frecuencia).
} 
versidades de Granada, de la UNED y de Valencia: las ya mencionadas de José Bernal y de Paco Vidarte así como la de María Valero, siendo -como ya se ha dicho- las dos primeras de una calidad realmente excepcional. A éstas, les seguirán las tesis, todas ellas asimismo dignas de mención, de Luis Aragón en 2004, Delmiro Rocha en 2010, Beatriz Blanco en 2011 (estas tres primeras defendidas en la UNED), Federico Rodríguez Gómez (2012, Universidad de Sevilla) y Vicente Medina (2014, UCM). Si, a todas estas tesis, les sumamos la docena (y aquí, me refiero exclusivamente a la UNED), más o menos, de trabajos de investigación centrados en Derrida que, desde 2001 hasta 2012, han venido realizando toda una serie de estudiantes para la obtención del Diploma de Estudios Avanzados así como, en estos dos últimos años, para los Trabajos de Fin de Carrera y de Fin de Máster, el panorama de la recepción del pensamiento de Derrida en España se torna bastante más esperanzador al constatar que los jóvenes, estudiantes, licenciados y doctores, se interesan cada vez más por su labor. Y, precisamente porque el porvenir de dicho pensamiento está en esas nuevas manos, a partir de aquí cedo en este artículo el testigo a uno de sus más idóneos representantes.

En efecto, el gran impacto que supuso la obra de Derrida a nivel internacional no fue ajeno a los círculos intelectuales españoles, si bien es cierto que - a pesar de honrosas excepciones - la onda expansiva de la deconstrucción alcanzó nuestro país con evidente retardo. No obstante, la influencia de una obra semejante siempre se produce a distintos niveles y según ritmos diversos. A este respecto la diferencia entre la recepción lenta - y a veces penosa - de la institución y la acogida jubilosa - y a ratos ingenua - de los investigadores marca una contradicción dramática por momentos. Entre otros, yo formo parte de esa contradicción.

Inicié la Licenciatura en Filosofía en la Universidad de Santiago de Compostela en el año 1999 y, a pesar de lo narrado por Cristina de Peretti en las páginas precedentes, el nombre de Derrida no resonó en las aulas de la Facultad de Filosofía del noroeste español hasta quinto curso. Gracias a Karina P. Trilles Calvo (Universidad de Castilla-La Mancha) - por aquel entonces una joven profesora contratada interina de substitución en la Facultad de Filosofía de la Universidad de Santiago de Compostela por un periodo de dos ańos- el temario de la asignatura "Corrientes Actuales de la Filosofía" fue pactado entre alumnado y profesora con la intención de guiar los intereses filosóficos de unos alumnos a punto de licenciarse. Muchos de nosotros aprovechamos la oportunidad de decidir, no siempre habitual en las aulas universitarias españolas, para demandar formación en pensadores contemporáneos, algunos de ellos todavía vivos, que de una forma u otra se imponían en el panorama internacional por llevar la interrogación de la actualidad, aquella en la que nos veíamos obligados a vivir 
pero no siempre forzados a pensar, hasta sus cuotas más elevadas de análisis. Pienso que esta carencia de actualidad en las aulas de filosofía todavía sigue siendo alarmante y quizá se deba a una estrategia equivocada. Cierto es que la comprensión histórica y los conocimientos previos son fundamentales para introducirse en los problemas filosóficos contemporáneos pero igual de elemental me parece el hecho de que los intereses que mueven la curiosidad, en particular la del alumnado, se mezclan las más de las veces con aquellas realidades que afectan directamente al interesado y que, por lo tanto, suelen tener su lugar en la inasible contemporaneidad. Quizá, entonces, el problema sea un problema de principio y de la idealidad del principio que, es sabido, las facultades de filosofía habitualmente sitúan en la Grecia clásica. Para Derrida, el comienzo absoluto no existe, el original se encuentra desplazado por su copia, debemos pues empezar quelque part où nous sommes (DERRIDA, 1967: 233). Buena muestra de la eficacia de este "comienzo" son los seminarios que Derrida impartía en lÉcole des Hautes Études en Sciences Sociales de París sobre temas de enorme actualidad filosófica y con un auditorio repleto de interesados. En cualquier caso, aprovechamos aquella ocasión para decidir parte de nuestro propio temario y, entre otros muchos autores de gran talla filosófica, apareció el nombre de Derrida. Así fue como tuvo lugar por primera vez bajo el tejado de la Facultad de Filosofía de Santiago una clase magistral sobre su pensamiento. Nótese que semejante hecho se produce en el curso académico 2003-2004, esto es, coincidiendo con los últimos pasos de la vida del filósofo. Hay que destacar el esfuerzo ingente de la profesora Trilles al preparar, casi sobre la marcha, una exposición de un pensamiento tan complejo y asistemático como el de Derrida, principalmente si tenemos en cuenta que el campo de especialización de Karina Trilles no se centraba en la obra de Derrida sino en la del filósofo, también francés, Merleau-Ponty. Más allá de la exposición, en la cual el alumnado participó como pudo, sin duda con más entusiasmo que acierto, aquel momento produjo en nuestras jóvenes e iniciáticas mentes filosóficas la certeza de que aquella música que sonaba bien a nuestros oídos, aunque pasaran desapercibidos la mayoría de sus arreglos, precisaba de una profundidad y atención mucho más graves. Convencidos de esta necesidad y conscientes de que la facultad ya nos había dado más de lo que cabía esperar, un pequeño grupo de alumnos decidimos montar un seminario paralelo a la enseñanza reglada con el único objeto de leer y discutir entre todos la obra de Derrida. El sublime motivo - aunque necio pues ignorábamos por completo cuán profundas eran las aguas de la deconstrucción - cristalizó formalmente en la creación de una asociación universitaria llamada "Seminario 67". La profesora Karina Trilles, en un acto de humildad filosófica, decidió unirse al grupo. Nótese que más allá de la personalidad determinada de la profesora en cuestión existe un elemento de parasitismo externo 
que determina el "acontecimiento", que de cierto modo impersonal provoca la llegada de algo nuevo, la ocasión para la ocasión. La apertura a estos tipos de parasitismos, entre otros, sería una de las condiciones para crear una institución que despeje el camino hacia el otro y avance, primero, hacia sí misma como otro. Nosotros, como ni siquiera sabíamos por dónde empezar con este otro que para los miembros del seminario se llamaba Derrida, y todavía empecinados en aquello de los comienzos, pues lo hicimos por donde creíamos que se encontraba el principio, a saber, por De la grammatologie. Ciertamente, no estábamos en condiciones de anticipar que en el interior de esa obra encontraríamos la respuesta a por dónde empezar y que no era esencialmente distinta, aunque sí paradójicamente circular, al motivo que nos había llevado hasta ella. A razón de una vez por semana, habitualmente los viernes por la tarde, nos reuníamos en el aula 67 de la facultad - de ahí el nombre del seminario - para desenmarañar lo intrincado de aquel pensamiento que tanto nos seducía. De De la grammatologie pasamos a La Dissémination (DERRIDA, 1972) y no dio para más aquel noble intento de abordar el corpus derrideano. Como es habitual en estos casos, las ganas de comprensión nos llevaron a consultar fuentes adicionales de información. Así fue como tuvimos noticia de especialistas como Cristina de Peretti, Paco Vidarte, Jose María Ripalda, Patricio Peñalver, etc. En medio del fragor y de la excitación comenzamos a confeccionar un congreso sobre pensamiento contemporáneo que habría de traer a nuestra arrinconada Galicia a los mejores especialistas españoles en deconstrucción. Alentados por los ánimos de la profesora Trilles surgió la posibilidad de traer al mismísimo Derrida como invitado de honor a nuestro congreso. La profesora Trilles realizó algunas investigaciones y pronto acudió al seminario con la triste noticia. Jacques Derrida estaba gravemente enfermo. La esperanza de traerlo a Galicia se esfumó en un segundo y con ella se fue al traste también nuestro congreso ideal. Mientras tanto el curso académico llegó a su fin. En reconocimiento al apoyo y a la valentía de la profesora Trilles la convertimos en madrina de la promoción y le otorgamos un lugar privilegiado en nuestra orla. Nos licenciamos y cada uno siguió su camino. Lo cierto es que no la he vuelto a ver pero aprovecho este espacio para agradecerle públicamente una labor que pone a las claras que si bien la excelencia académica es un requisito honorable y exigible al profesorado para la correcta formación del alumnado también lo son, o así debiera, el denuedo y el entusiasmo. Sirvan estas pocas líneas como sincero homenaje. Y no es para menos pues lo que vendría después sería, si cabe, de mayor calado. Aquel Seminario 67 sirvió no tanto para aprender las estrategias textuales de la deconstrucción como para querer aprehenderlas. Semejante querencia nos llevó a algunos integrantes del seminario a matricularnos en los cursos de doctorado que impartía el Departamento de Filosofía de la UNED en Madrid. Así conocí personalmente a especialistas 
en deconstrucción de la talla de Cristina de Peretti, Paco Vidarte o Jose María Ripalda. Poco a poco fui adentrándome en el terreno derrideano de la mano de estos y otros excelsos ejemplos realizando diversos trabajos. Primero realicé mi trabajo de investigación titulado "La substantivación (sin substancia) del adverbio quizá en la filosofía ético-política de Jacques Derrida” bajo la dirección de Cristina de Peretti. Seguidamente, y ya trabajando como becario de investigación FPI-UNED en el Departamento de Filosofía realicé una cotutela internacional de tesis doctoral dirigida por Cristina de Peretti y Manuel Suances (UNED) y Thomas Dutoit (Université Charles-de-Gaulle, Lille3, Francia) titulada "Muerte del dinasta. La contaminación iterable de lo propio en Jacques Derrida". Estos trabajos especializados en el pensamiento de Derrida son sólo dos muestras de lo que posibilita la estructura armada por el grupo Decontra y el grupo de investigación Deconstrucciones que si bien de forma humilde constituye, junto a unos pocos profesores más bien dispersos por la geografía española, casi el único resquicio académico desde el cual la deconstrucción logra arañar un espacio institucional.

De alguna forma en España pero al margen de la institución, de la capital y de la lengua espańolas surgió en 2006 un lugar donde el pensamiento de Derrida encontró acomodo para expresarse y expandirse. Un grupo de gallegas y gallegos, en su mayoría licenciados en filosofía, entre los cuales nos encontrábamos algunos de aquel "Seminario 67" anteriormente referido, decidimos asociarnos para trabajar en favor de la investigación en pensamiento contemporáneo. Así nació el colectivo Proxecto Derriba, ${ }^{8}$ con una presencia virtual en las tres uves dobles y con dos grandes objetivos. Por un lado, colmar un vacío investigador en el campo de la filosofía contemporánea en Galicia y, por otro lado, crear un vocabulario filosófico específico inexistente en lengua gallega - lengua lusófona oficial de la región de Galicia (España) - a través de estudios y traducciones de autores contemporáneos. Todos los materiales están subidos a la red y sometidos a licencias libres con la intención de crear una serie de herramientas pro-común. Así, al menos, se expresa en la colección de monografías de pensamiento contemporáneo que edita el colectivo en colaboración con Estaleiro Editora. ${ }^{9}$

\footnotetext{
${ }^{6}$ Trabajo publicado recientemente en lengua gallega: ROCHA, Delmiro. Quizais. Filosofía éticopolitica do porvir. Vigo: Euseino Editores, 2014.

${ }^{7}$ Trabajo publicado en castellano con un prólogo de Cristina de Peretti: ROCHA, Delmiro. Dinastías en deconstrucción. Leer a Derrida al hilo de la soberanía. Madrid: Dykinson, 2012.

${ }^{8}$ Diponible en: <www.proxectoderriba.org $>$.

${ }^{9}$ Todas las monografías del colectivo recogen este texto al final de la obra bajo el epígrafe "Materiais e ferramentas procomún": "Co obxectivo de avanzarmos na forxa dunha linguaxe e un vocabulario específico en galego que teña en conta a problemática filosófico-política contemporánea e co obxectivo tamén de nos afastarmos da mera tradución do castelán, propomos unha lińa de textos monográficos de autoría contemporánea. A colección, dirixida tanto ao público universitario en xeral como ao
} 
El número 4 de la colección dedica su monografía a Derrida (ROCHA, 2011). Más allá de la introducción a su pensamiento, esta obra -igual que los otros seis números publicados hasta el momento y dedicados a otros pensadores contemporáneos- tiene el aliciente de ofrecer a la lusofonía en general una selección de textos de toda la obra de Derrida traducidos por primera vez al gallego. Asimismo, el colectivo Proxecto Derrida edita desde el año 2007 una revista semestral de filosofía llamada Derritaxes ${ }^{10}$. En ella la presencia de Derrida es altamente significativa. ${ }^{11}$ A esta doble tarea editorial - colección de monografías y revista semestral -, doble tarea que no trata simplemente de crear discurso filosófico alternativo sino que pretende interferir en el discurso filosófico establecido, hay que añadir un tercer elemento consistente en la organización e impartición de cursos de formación en los cuales la figura de Derrida acostumbra a estar sistemáticamente presente. Como la deconstrucción, esta labor tiene efecto sobre la institución desde una posición marginal. Ciertamente, los cursos se realizan dentro y fuera de la institución universitaria y de alguna manera, en un vaivén de investigadores que entran y salen de los muros académicos desplazando su presencia y sus discursos, la institución se ve afectada por

persoal docente de filosofía, procura iniciar unha investigación propia na obra dun autor ou autora, preencher un baleiro específico dentro da teoría en lingua galega e, ao mesmo tempo, dispor dunha escolma de documentos orixinais e fixar un vocabulario conceptual inexistente en galego. Os textos son elaborados polas persoas investigadoras do colectivo Proxecto Derriba tentando que a precisión técnica e a contemporaneidade non sexan un impedimento para o seu carácter pedagóxico."

${ }^{10}$ El nombre de la revista "Derritaxes" es una traducción al gallego del título de la tesis doctoral de Paco Vidarte - anteriormente reseñada - publicada en francés bajo el neologismo "Derritages". La revista edita todos sus números en su memoria. En junio de 2008 se publica un número especial denominado "Derritaxes Exprés. Un tal Paco Vidarte" dedicado en exclusiva a su pensamiento.

${ }^{11}$ Enumeramos a continuación los artículos publicados en la revista Derritaxes en los cuales el pensamiento de Derrida es tratado de forma exclusiva o bien tiene una presencia determinante:

HAUSER, Sören. "Acontecemento postmoderno e pulos utópicos", n. 0, Diciembre 2007; HAUSER, Drocha. "Unha deconstrución da soberanía 'A paso de lobo'. Lendo un(s) texto(s) de J. Derrida", n. 0, Diciembre 2007; HAUSER, Sören. "A utopia en Europa ou a malla das mallas", n. 1, Junio 2008; HAUSER, Drocha. "Recensión de 'Seminario A Besta e o Soberano' de Jacques Derrida", n. 2, Diciembre 2008; VIDARTE, Paco. "Dunha certa cadencia en deconstrución”, n. 3, Junio 2009; HAUSER, Beatriz, HAUSER, Sören, HAUSER, Drocha. “'Traducir ao outro'. Entrevista con Cristina de Peretti (Adirías Hauser)", n. 3, Junio 2009; HAUSER, Drocha. "Nunca souben contar unha historia", n. 4, Diciembre 2009; RIPALDA, Josemari. "Carta a unha amiga galega”, n. 4 Diciembre 2009; HAUSER, Drocha. "Recensión de 'Conjunciones. Derrida y compañía' del Grupo Decontra”, n. 4, Diciembre 2009; HAUSER, Drocha. "Recensión de 'Séminaire La bête et le souverain II (2002-2003)' de Jacques Derrida”, n. 5, Junio 2010; DUTOIT, Thomas. “'Ser atrapado e ser aforcado': Autores do golpe, a pena de morte", n. 6, Diciembre 2010; HAUSER, Drocha. "Deconstrución de 'O Rei Lear' de Shakespeare: Acto I", n. 6, Diciembre 2010; HAUSER, Drocha. "Fe na universidade", n. 7, Junio 2011; HAUSER, Beatriz."Da biopolítica á ecopolítica”, n. 9, Junio 2012; HAUSER, Sören."Deconstrucións e outro. Unha fantoloxía do acontecemento", n. 10, Diciembre 2012; HAUSER, Beatriz."Restos da lingua", n. 11, Junio 2013; HAUSER, Drocha. "A escritura poética ou a douta ignorancia", n. 11, Junio 2013. 
el parasitismo y la contaminación de dicho proceso. ${ }^{12}$ Es la diferencia entre una crítica a la institución, la cual la institución albergaría con desahogo y aplauso, y la deconstrucción de la institución, la cual no encuentra jamás acomodo ni simplemente dentro ni radicalmente fuera. Quizá se encuentre aquí el punto problemático de la recepción de Derrida en España, al menos la inicial, pues la mayoría de los principales artífices de la misma pertenecen a la institución filosófica y la propia diseminación que la deconstrucción porta vuelve problemática la asimilación institucional. No obstante, este es precisamente el interés de la deconstrucción cuando piensa la institución y, desde tal ángulo, la recepción española de Derrida se vuelve un interesante ejemplo. Se puede observar con facilidad la enorme diferencia que supone la recepción de Derrida en los EEUU - lugar que ha enaltecido de forma determinante la labor de la deconstrucción -, la cual se produce fundamentalmente en los departamentos de literatura. Aunque, como la deconstrucción, el caso español se dice en plural. Como es sabido, las diferentes realidades culturales, las diversas lenguas de asimilación y los importantes niveles de autonomía educativa de las regiones que dividen y forman Espańa dibujan un mapa variopinto y dispar de la recepción que nos ocupa. A este respecto, podemos encontrar cierta asimilación institucional, gracias al trabajo incansable de algunas y algunos, en lugares como Madrid, Cataluña, Murcia o País Vasco y contraponerla con el caso gallego - que aquí trato de esbozar - donde los predicados derridianos llegaron a la institución desde su afuera más inmediato. Sea como fuere, la difícil acogida del discurso deconstructivo por parte de la universidad no pone en jaque simplemente a determinada institución u organismo, a pesar de que sin duda se nutre de su singularidad, sino que revela la problemática misma del concepto moderno de universidad como pirámide del saber, como todo enseñable, como concepto filosófico general que primero encierra su esencia en una facultad particular $y$, actualmente, pretende abandonarla a la fatalidad que el destino económico le depare. Pero la deconstrucción no se posiciona del lado de aquellos que quieren acabar rápidamente con la filosofía y que agitan banderas celebrando verbosamente su muerte ni tampoco se aferra sin más a cualquier defensa a ultranza de la filosofía que, según Derrida, no hace otra cosa que facilitar la tarea a las empresas liquidadoras (DERRIDA, 1990: 120). De esta forma, la deconstrucción no pretende substituir un modelo de universidad donde predomina la Idea kantiana por otro donde mande el modelo deconstructivo pues ella no ha sido jamás un corpus metodológico,

\footnotetext{
${ }^{12}$ A este respecto cabe señalar al profesor Francisco Conde, miembro del colectivo Proxecto Derriba, que desde su ingreso en la Facultad de Filosofía de la Universidad de Santiago de Compostela en diciembre de 2010 ha impartido abundante docencia con Derrida como protagonista a pesar de que su especialidad se centra en el pensamiento de Edmund Husserl.
} 
un proyecto o sistema filosófico, ni siquiera una filosofía como tal (DERRIDA, 1992: 367). Más bien, la deconstrucción habita singularmente la institución, la asedia, está en ella antes de llegar a ella como discurso. Esto hace que - debido a que el proceso de instrumentalización, que la deconstrucción sin duda recibe y recibirá, no puede cerrarse por definición bajo algo así como una "institución deconstructiva" y más allá de la labor de subjetividades singulares a las que aquí hemos referido y que, por otra parte, son imprescindibles en este transcurso - la universidad posibilite el espacio para que algo nuevo suceda. Un asedio que no es ciertamente impersonal ni reside sin más en sujetos particulares pero que provoca a la institución para que se abra al acontecimiento, también a la deconstrucción como acontecimiento, y en primer lugar al acontecimiento de abrirse al acontecimiento: ça se déconstruit.

\section{Referências bibliográficas}

BERNAL, José. El desplazamiento de la filosofía de Jacques Derrida. Granada: Universidad de Granada, 2001.

CIXOUS, Hélène; DERRIDA, Jacques. Lengua por venir/Langue à venir. Seminario de Barcelona. Ed. M. Segarra. Barcelona: Icaria, 2004.

DERRIDA, Jacques. "Circonfession". In: BENNINGTON, Geoffrey; DERRIDA, Jacques. Jacques Derrida. Paris: Seuil, 1999a.

. "Poétique et politique du témoignage", Prosopopeya. Revista de crítica contemporánea, n. 1, Valencia, outono-inverno 1999b.

. Moscou aller-retour. Paris: Éd. de l'Aube, 1995a.

. Mal d'archive. Une impression freudienne. Paris: Galilée, $1995 \mathrm{~b}$.

. "L'oreille de Heidegger. Philopolémologie (Geschlecht IV)". In:

Politiques de l'amitié. Paris: Galilée, 1994a.

. Force de loi. Le "Fondement mystique de l'autorité". Paris: Galilée, $1994 \mathrm{~b}$. . Points de suspension. Entretiens. Paris: Galilée, 1992.

. Du droit à la philosophie. Paris: Galilée, 1990.

. La filosofia como institución. Trad. A. Azurmendi. Barcelona: Juan Granica, 1984.

. La Dissémination. Paris: Seuil, 1972.

. De la grammatologie. Paris: Minuit, 1967.

ESCRITURA e imagem (UCM). Actas del Coloquio Internacional de Derrida/Héritages de Derrida. Madrid. 24-26 fev. 2010. Volume extraordinário.

ROCHA, Delmiro. Deconstrucións. Unha volta a Jacques Derrida. Ourense: Estaleiro, 2011.

VIDARTE, Paco. Derritages. Une thèse en déconstruction. Paris: L'Harmattan, 2001. 
Cristina de Peretti es profesora de Filosofía en la UNED (Madrid, España) y especialista en el pensamiento de Derrida. Además de ser autora dos monografías - Jacques Derrida. Texto y deconstrucción (Barcelona: Anthropos, 1989) y (con P. Vidarte) Jacques Derrida (Madrid: Ed. del Orto, 1998) - y de numerosos artículos sobre Derrida, ha dirigido algunas obras colectivas dedicadas a su pensamiento. Asimismo ha traducido varios de sus textos al espańol, los tres últimos para editoriales argentinas.

Delmiro Rocha es Doctor Europeo en Filosofía por la UNED, Ph.D por la Université Lille 3 (Francia), Premio Extraordinario de Doctorado, profesor-tutor de la UNED, integrante de Proxecto Derriba y traductor de Derrida. Ha publicado Dinastías en Decosntrucción. Leer a Derrida al hilo de la soberanía (Madrid: Dykinson, 2012) y, en gallego, Decontrucións. Unha volta a Jacques Derrida (Ourense: Estaleiro, 2011) y Quizais. Filosofía ético-política do porvir (Vigo: Euseino, 2014). 